\title{
A Discussion of the Treatment of People with an Intellectual Disability Across Healthcare and the Modernization of Learning Disability Nursing
}

\author{
Pamela Inglis ${ }^{*}$, Hazel Powell, Angela Ridley and Sheila McQueen \\ Department of Public Health and Wellbeing, Faculty of Health and Life Sciences, Room B017 Coach Lane \\ Campus West, Benton, Newcastle, NE7 7XA, UK
}

\begin{abstract}
Aims: A discussion of the treatment of people with an intellectual disability across healthcare and the modernisation of learning disability nursing.

Background: Health inequalities are at the forefront of the collective mind of healthcare professionals and politicians, this paper explores why people with an intellectual disability have more health issues, die earlier and sometimes receive poor care, leading to unnecessary suffering and importantly, how this may change. Learning disability nursing has long been viewed as different and less valued, probably due to dual stigmatisation, or lack of understanding of specialist knowledge and skills required. This essential field of nursing is becoming a rare resource in our battle against health inequalities, yet internationally it is becoming recognised as crucial.
\end{abstract}

Design: Discussion Paper.

Data Sources: Literature and policy $(1971-2012)$.

Implications for Nursing: All nurses need to recognise their role in meeting the health care needs of people with an intellectual disability. Health care managers and commissioners should value the unique contribution of learning disability nurse in addressing health inequalities.

Conclusion: Learning disabled people, their carers and professionals view the role of the learning disability nurse as central for effectively identifying and meeting health needs, reducing inequalities and barriers, supporting decisions around capacity, consent, best interests and advising and educating professionals. Recommendations for commissioning, nursing and services are made.

\section{Summary Statement:}

Why is this discussion paper needed?

People with an intellectual disability have shorter life-spans and receive poor healthcare because of the barriers to good health developed in societies constructed by and for people without a disability.

Internationally, the need for learning disability nurses, with their specific knowledge and skills, is being recognised in the battle against early and unnecessary deaths because of discrimination and health inequalities.

Learning disability nurses and 'Strengthening the Commitment' lead on improving healthcare for learning disabled people and this paper raises the profile of this important health issue.

What are the key findings?

This discussion paper explores how most of the poor health experienced by people with an intellectual disability is about discriminating healthcare provision and crucially, not because the person has a disability.

People with an intellectual disability have greater health needs than others and despite this, nonspecific health professionals often have scant understanding of their disability and health needs.

Learning disability nursing as a vital resource has in recent years seen posts reducing in the NHS, with actual and commissioned numbers of registered learning disability nurses dropping.

How should the findings be used to influence policy/practice/education/research?

People with an intellectual disability and nonspecific staff often feel they are inadequately educated and lack appropriate skills for quality healthcare provision for learning disabled people; this has to change.

Sir Johnathon Michael (2008) recommendation 1 advises that all health professionals be competent in supporting learning disabled people in a non-discriminatory way - universities and employers urgently need to adhere to this recommendation.

Professionals, learning disabled people and carers state learning disability nurses are vital to acquiring human rights increased international commissioning for learning disability nurses to enable quality healthcare, education and advice to professionals is pressing.

Keywords: Nursing Practice, Learning Disability, Health Inequalities, Policy, Professional Issues.

*Address correspondence to this author at the Department of Public Health and Wellbeing, Faculty of Health and Life Sciences, Room B017 Coach Lane Campus West, Benton, Newcastle, NE7 7XA, UK; Tel: 0191 2156163; E-mail: pamela.inglis@northumbria.ac.uk 


\section{INTRODUCTION}

In Britain there are 1.5 million people who have an intellectual disability [1]; and this is predicted to increase by $14 \%$ over the next decade [2]. This is about as many people over the age of 40 that have Type 2 diabetes, therefore, constitutes a substantial health issue [3]. Often people with an intellectual disability do not have access to essential aspects of life such as relationships, housing, timely appropriate healthcare, treatment and information. Crucially most of the problems regarding accessibility are not because of the persons impairment, but because society does not enable equal access to services for people that have particular difficulties. In fact, whilst the life span in the general population is increasing, the learning disabled population are more likely to die before the age of 50 and causes differ from the rest of the population [4].

In Britain we have learning disability nursing as a distinct field (RNLD); the only health professionals (HP's) world-wide that are educated specifically to work with people with an intellectual disability [1]. Unfortunately, this vital resource has been drained from the National Health Service (NHS), with commissioning dropping [5].

Internationally there had been moves from medical type care for people with an intellectual disability towards more social aspects. Learning disability nursing includes aspects of both, as we have a philosophy of care that is holistic, and the false divergence created by the health and social care funding is not useful to us. We cannot ensure good health without good housing, benefits, access to information and quality relationships. Physical and mental health does not exist or improve in a vacuum. Therefore learning disability nurses:

Continue to play a crucial role in moving the care of people with learning disabilities... to communities, in championing health improvement and working to tackle the health inequalities experienced by those they work for (1 $\mathrm{p}$. 7).

World -wide, there is a dawning recognition for specific fields of nursing for this purpose [6]. Nearer to home, the Nursing and Midwifery Council (NMC) retained all four fields after a major consultation [7] and the four UK Health Departments has recently produced its excellent report on the modernisation of learning disability nursing entitled 'Strengthening the Commitment' (STC) [1] both of which endorse the specific skills and vital contribution of the RNLD.

Yet people with an intellectual disability have poorer health than the rest of the population, are suffering more and are even dying unnecessarily in our hospitals and care facilities [8]

'there is also evidence of a significant level of avoidable suffering due to untreated ill health, and a high likelihood that avoidable deaths are occurring.' (9 p. 21).

We have a limited number of RNLD's, evidence of unmet need and increased susceptibility to discrimination and violation of Human Rights as needs are misunderstood by other HP's.

Therefore, this discussion paper will review ways in which people with an intellectual disability have poorer health, the role of the RNLD, the importance of this resource and the need for a knowledge based and philosophical shift among HP's world-wide, to effectively care for people with an intellectual disability. A considerable task as the World Health Organisation [10] reports there are 650 million people world-wide with a disability (probably an underestimation due to non-detection, misdiagnoses, diagnostic overshadowing, as well as isolation and social stigma).

\section{SOCIETAL CONTEXT}

Next the paper explores how society views people negatively and how this effects their quality of life and subsequent health care. Philosophically, it questions whether an intellectual disability is viewed as an individual issue or as being fashioned out of a society developed for people without an intellectual disability therefore disadvantaging them. Clearly, this is an important issue which may be contextualised through re-visiting the historical aspects effecting this population.

Historically, people with learning disability have been labelled in many negative ways and with more positive markers such as the Irish 'Duine Le Dia', literally meaning 'someone with God'; someone special. Whether viewed negatively or positively; people with an intellectual disability have been literally set apart from the rest of society, and this segregation takes several forms that effect many aspects of their lives. 
One of the ways in which we may set people apart is through a notion called the Personal Tragedy Model viewing disability as a tragedy, and enabling sympathetic treatment [11], leading to oppressive ways of viewing people as unable to self-care or make good decisions.

If nurses accept this view of learning disability then this can negatively effect the way in which they deliver health care. Investigators such as Nellie Bly (Reporter in 1887) and Erving Goffman (1968) studied the treatment of people in long stay institutions and found that the pitiable ways in which people were treated were not merely because of poor staff attitude and overcrowding, but through lack of knowledge and skills, and false beliefs about people with an intellectual disability. Additionally the presence of such institutions ensured that other HP's could almost abdicate their responsibility in this area.

The current poor experiences of people with an intellectual disability are systemic, as well as related to a lack of knowledge and skill and are highlighted in reports such as 'Death by Indifference' and recommendations by an Independent Inquiry, proposing we must educate all HP's to deliver excellent care to people with an intellectual disability [9].

New ideas began to emerge mid-century, together with adverse reports from the institutions and pluralist groups [12]. In 1958, Jaques Tizard showed that providing a more ordinary and stimulating environment for children brought improvements in their cognitive ability and behaviour. Giving the first glimpse of evidence that it was the ways in which people were treated that created poor physical, intellectual and emotional health; not purely their learning impairment.

It was a combination of Nations Declaration of Rights of the Disabled [13] (1971 and 1975), and Better Services for The Mentally Handicapped (1971) [14], which began the reduction of the number of people institutionalised and put an end to automatic hospitalisation (The National Development Group, 1977) [15].

The medical model is similar to the personal tragedy model as it sees difference as being within the person, and as something that is likened to a sickness or disease. Often learning disability nursing is associated with the medical model and it is presumed that part of our role is to somehow 'treat' the learning disability, but of course this is not so.
The roles of RNLD's include working in partnership with people with an intellectual disability, other HP's, stakeholders and families to empower people with an intellectual disability to live healthier and happier lives.

During the 1970's Wolf Wolfensberger proposed that people with an intellectual disability should be offered a life as close to normal as possible (named, normalisation) [12]. These ideas were based upon human rights and role theory but unfortunately its claims to be scientific are questionable [16]. Importantly, this message is about changing the behaviour of people with learning disability in order to be accepted by society, not about changing society, perse. It postulates that disabled people can be elevated in the eyes of society, through normalising themselves. Generating potential pressures to achieve upon learning disabled people, without evidence of increased acceptance [17-19].

What is important about this brief history above is to note that people with an intellectual disability historically had little say over the ideologies effecting them, as they emerged from and were developed by academics and professionals - that is until the emergence of the social model of disability.

Challenges to our beliefs about disability primarily began with The Union of the Physically Impaired Against Segregation [20] that produced 'Fundamental Principles' to liberate people with impairments. This document was significant in the development of the social model that proposes that disability itself has been constructed as a form of a social problem.

Whilst most people may now accept the social model of disability, it may be difficult to contemplate that learning disability is not about the intellectual impairment but about how we as a society construct learning disability.

Whether 'learning disability' is an absolute at all is debatable [21] as in 1969 the American Association on Mental Deficiency placed the Intelligence Quotient (IQ) threshold for learning disability at 85 - this is one standard deviation away from the normal score of 100 . Consequently, $16 \%$ of the American population were diagnosed learning disabled [22]. In 1973 this was adjusted to two standard deviations from 100 - a score of 70 or below (the present threshold for learning disability), and only $2.25 \%$ of the population was then categorised as having an intellectual disability [22]. This means that almost overnight nearly $14 \%$ of 
Americans were cured of learning disability and constitutes an attractive argument for the social construction of learning disability.

It is through societal problems ranging from poor attitude and low expectations through to more practical things like accessing health care that disables people, not their learning impairment. For the first time disablement moved from the individuals' problem to a social problem.

Negative ideologies are challenged by the social model, that shows they can lead perfectly happy and fulfilled lives. Even requiring 24-hour support does not mean that their lives are unfulfilled - but a value judgement based on someone else's experience. Lives may be different and still be rewarding and important.

Finally The Community Care Act (1990) ensured that people would have to be cared for within the community, rather than institutions.

Around the turn of the century the Affirmation Model [23] emerged from views of disabled people to reflect the beliefs that people who are disabled do not have to change. Society should re-frame their experience in a more positive way as having impairments can have benefits. Indeed some disabled people have received better education and escaped poor backgrounds because of their disability. The 2012 Paralympics showcased trailers featuring athletes proclaiming a wish not to be other than disabled - at peak viewing time on an international stage - demonstrating exactly what the affirmation model postulates. Disabled people do not need to change; but their experiences with services can change with a shift in attitudes, beliefs and practices by services and professionals.

In 2001 the Government released - Valuing People: A New Strategy for Learning Disability for the $21^{\text {st }}$ Century which was fashioned in consultation with people with learning disability and looks at the current problems and challenges; health, ageing, housing, employment services, quality, supporting carers and delivering change for the better. It remains updated and forms part of the future strategy for healthcare for people with an intellectual disability.

Professor Dan Goodley worked with a self advocacy group of people with an intellectual disability that argue that self-advocacy offers important collective opportunities for the development of confidence and challenging oppression. One of the main ways in which this is done is through challenging the negative views surrounding people with learning disability through 'accentuation of the positive' [24 p. 12] overturning notions of dependency and emphasising abilities and attributes. At last people with an intellectual disability have opportunities to shape future services.

Intrinsically interlinked with the changing views are evolving services and the developing role of the RNLD. The shift from institutional to community based care reduced the apparent demand for learning disability nurses as a specialism and the current workforce is smaller and more widely distributed across the health and social care sector than ever before; reducing focus and direction for learning disability nursing and consequently, a loss of specialist nursing skills - at a time where health needs are increasing and not being met [1].

The crux of the disabled movements' arguments and one that can run deep in and across society; and of course, nursing philosophy - is that disabled people are not just healthy, ill, Paralympians and/or impaired, but are disabled by society. The barriers that disabled people have to good quality health care are commonly created by lack of resource, knowledge and skills, as well as inflexible services and practitioner attitude.

\section{HEALTH INEQUALITIES}

One of the main barriers to good health for people with an intellectual disability is related to beliefs held by HP's - the Michaels report (9 p. 18) states:

Sometimes... treatment is not offered to people with a learning disability because a judgement, albeit an inaccurate one, is made about its value. Such judgements imply that a life lived with learning disability is a life less valued. In other cases, symptoms occurring in patients with a learning disability are misjudged.

Symptoms which they display may be overshadowed by the diagnosis of their learning impairment.

'Witnesses reported that the phenomenon is widespread, and is particularly problematic in palliative care or when someone with a learning disability is in pain and can only communicate distress through behaviour (such as screaming or biting) that staff find challenging and/or difficult to interpret' Michaels Report (9 p. 18). 
Often referred to as 'diagnostic overshadowing'; HP's mistakenly believe that symptoms are features of the learning disability, rather than physical or mental ill health - therefore the diagnosis of learning disability overshadows any other reasonable diagnosis. Consequently, people with an intellectual disability are suffering needlessly and dying unnecessarily [9]. Poor health care appears more clearly related to the lack of accessible materials, health care they receive, and practitioner beliefs, rather than their impairment.

Next the paper will describe the ways in that heath care is effected by such issues, and discusses its implications for nursing.

People with an intellectual disability have greater health needs than the rest of the population, as nonlearning disability specialists often have a scant understanding of their needs [9]. We know this through adverse reports $[4,25]$ meaning that people with an intellectual disability are at higher risk of:

- $\quad$ coronary heart disease and cardiac anomalies including those associated with specific syndromes

- gastrointestinal cancer and stomach disorders

- respiratory disorders from which they are three times more likely to die

- $\quad$ sensory impairments

- weight anomalies

- dementia and mental health issues [4-6, 9, 2629].

Additionally, approximately 2 out of every 3 carers/family members are required to stay in hospital to support patients with an intellectual disability, and some people and their family report poor experiences of care.

However, by small and humane changes to hospital and ward policies their experiences can easily be improved. Using reasonable adjustments and hospital passports or utilising Liaison Nurses can help improve the care experience for example:

- $\quad$ arranging for carers to come to the recovery area as soon as the patient recovers consciousness to help reduce anxiety

- or rehearsal visits to a department can be made before admission.
The Michaels Report, valuing people and STC come together there and form a very strong message to all health care professionals: People with an intellectual disability have the same rights as everyone else under the Human Rights Act (1998) [30], and Equality Act (2010) [31] and it is our moral and professional responsibility to understand their needs and make fair and reasonable adjustments - meaning skills, knowledge and attitudes of health professionals and services will have to change.

The social issues effecting people with an intellectual disability include; a lack of choice and a reliance on others to create healthy opportunities, little access to relevant health promotion information, which is not always in accessible forms. Essentially this may be viewed as a form of oppression and discrimination by health promotion providers. Often they have poor experiences in using services which encourage low attendance. Generally, they are considered more vulnerable and more likely to have suffered sexual and physical abuse and bullying [32].

They are often living in poverty (as they may not have access to employment), which includes poor housing, have few resources (such as friends and colleagues) to call upon; have a poor diet, social restrictions and isolation. Commonly they may be put off visiting HP's because of difficulty in accessing information about screening, nutrition, immunisation, contraception, exercise and life style factors - such as smoking cessation [9].

Following a public Inquiry into early and unnecessary deaths of six people with an intellectual disability in England Sir Jonathan Michael talked to many people; professionals, families, carers and people with an intellectual disability and concluded that there were many faults with our current health care system.

It made ten recommendations the first of which was about the education of professionals to work with people with an intellectual disability in a nondiscriminatory way. This education must include the authentic involvement of people with an intellectual disability and obviously it has implications for pre and post registration nursing [9]. Internationally, this may only change if Learning disability nursing is commissioned outside as well as inside the UK.

\section{REVIEW OF LEARNING DISABILITY NURSING}

In 2011 the UK review of learning disability nursing was commissioned and led by the Chief Nursing Officer 
for Scotland on behalf of the Chief Nursing Officers across the UK. It reflected a UK commitment to gathering and considering evidence on the future contribution of RNLD's. The processes included literature reviews, the collection of positive practice examples and visits to practice and education settings. Nurses and students were involved through workshops, conferences, focus groups and social media and two UK wide events were held for educationalists and professionals working in the independent/voluntary sector.

Each country had a steering group with a wide range of stakeholders including people with learning disabilities and their family. In addition to hosting the UK co-production steering group, the Scottish Consortium for learning disabilities held focus groups for children, young people, people receiving support from forensic services and parents and carers of people with complex needs living in remote and rural areas.

It found that RNLD's remain important in the eyes of people with an intellectual disability, their family and other professionals. Learning disabled people told the review that RNLD's respect and listen to them and help them to manage their health, families told the review that without RNLD's their son or daughter would not be receiving the health care they need and deserve. Additionally, other professionals reported that they could not do their job without the support of RNLD's; liaison nurse roles were particularly valued. The value base of RNLD's was cited as strong and a vital element; which may be instilled across all HP's.

RNLD's are seen as responding in a creative, flexible and effective manner, based on clear values that include placing people at the centre of care and acknowledging the critical contribution of family/ carers - they are just too thin on the ground [1].

The review resulted in the report Strengthening the Commitment [1] based on the themes of strengthening capacity, capability, quality and the profession. The report makes 17 recommendations that aim to support the development of new roles, ensure that the skills and competence of RNLD's are available across the lifespan, develop sophisticated workforce planning, develop collaborations across sectors and ensure that education provides high quality and flexible support across the career framework.

A UK steering group has been set up and each country has developed their national implementation groups and action plans, these will ensure that people who have an intellectual disability rightly receive person centred, safe, and effective everyday and specialist healthcare services.

Primary legislation states that services and organisations must be adjusted to fulfil their requirements under the Equality Act [31] (although this replaces most of the Disability Discrimination Act, 1995 [33] (DDA) the equality duty in the DDA still applies) and must offer people with an intellectual disability:

- accessible information

- $\quad$ longer and accessible appointments

- $\quad$ timely identification of learning disability

- $\quad$ appropriate treatment

- $\quad$ screening programmes

- $\quad$ alleviation of health inequalities

- $\quad$ reduction in the gap in life expectancy

Unfortunately, the latest report on unnecessary deaths of people with an intellectual disability states that there are currently 74 avoidable deaths identified. This number is expected to grow, as is the immediate need for change and redress [4].

\section{IMPLICATIONS FOR NURSING}

The strengths of RNLD's alluded to earlier provide a solid foundation for the development of good healthcare within the current demographic and policy context. There is a lot to celebrate but it is right that as an accountable and forward thinking profession RNLD's set the direction of travel and ensure that people with an intellectual disability get the learning disability nurses they want, need and deserve.

Meanwhile there are modifications that individual practitioners, organisations or policy developers might utilise to improve health outcomes of this population. Generally, what will be helpful to people with an intellectual disability would be that everyone remembers that people with an intellectual disability:

- have a legal and moral right to good quality health care

- $\quad$ are not always able to communicate symptoms

- $\quad$ utilise different communication 
- $\quad$ require information - jargon-free, clear and brief.

There are lots of ways in which people with an intellectual disability can gain access to quality health services, and this can be successful across many levels. For example, policy and law makers ensuring statutory provision is in place and adhered to at the level of commissioning for adequate numbers of RNLD's and recognition of their unique contribution; offering incentives to GP's, to deliver annual health checks; and through people with an intellectual disability taking part in local health boards and committees with influence. They should be Included in all health improvement initiatives and they also have legal protection and lawful recourse available when things go wrong.

In working at advanced level of practice, individuals are required to have a high level of awareness of their own values and beliefs. Care is negotiated with service user/carers as an equal partner. Working in a positive and constructive way with difference and diversity and putting the values, views and understanding of individual service users and carers at the centre of everything is essential to all advanced nursing roles (Scottish Government Health Departments 2008; ICN 2001) [34].

Moreover, every practicable step should be taken to ensure that systems are available in formats that are accessible. Equality and diversity are best served by Investing in the workforce to provide support, training, education and of course, commitment to continuing professional development, therefore quality education is paramount.

But what is most important for this section, is what can be achieved on an individual level practicing with a person who has an intellectual disability. Firstly, and what may be very beneficial to the individual and their family, is seeing the individual and not just the disability whilst ensuring that the person with an intellectual disability has access to specialist services when required. This can be done through contacting your local learning disability community nursing team to help with aspects of physical and mental health through things like, assessments, monitoring, clinical interventions and referral to specialist teams. They may help with simple changes to care that can make a positive difference to their experiences, just by listening carefully and making small adjustments; for example;

Sally was admitted to a Day Surgery Unit, she has Rett Syndrome, a neurodevelopmental disorder and will hold her breath as part of her condition, this is important to know when caring for her post general anaesthetic, this information was in her hospital passport, to which the liaison nurse directed staff. Her parents expressed anxieties about challenges linked to her condition and treatment, such as their the potential risk of an epileptic seizure in a public area, or how she might manage with her toileting needs. In response to this Sally was offered a private bed space, with a disabled toilet. Sally loved to listen to music, so it was arranged that her favourite music was played in the anaesthetic room and that she could be accompanied by her mum to minimise her anxieties.

In addition specialist knowledge, referrals, health facilitation nurses and basic tools are useful, such as:

- $\quad$ Passports are used to enable non-specialist staff to quickly access vital information about patients such as preferred forms of communication.

- Individual HP's can developing interesting and fun ways of enabling people with an intellectual disability to access health promotion materials, through e.g. rehearsal and pictures

- Share good practice and reflect upon the mistakes of the past learning from them [35].

- RNLD's may help to ensure that patients have good access to quality healthcare and as HP's can access such experts.

- $\quad$ Health facilitation nurses offer important access to acute and primary health care, health action planning and annual health checks.

Health action plans offer individual opportunity for comprehensive assessment and planning for physical health needs, are reviewed annually and offer guidance for HP's in primary care, and information for the individual, their carers and family, aiding in good access to healthcare.

Importantly, learning disability nursing has a crucial part to play in health improvement and working to tackle health inequalities experienced by people with learning disabilities. Strengthening the Commitment (1 p. 9) outlines the central roles of learning disability nurses as: 
- $\quad$ Effectively identifying and meeting health needs

- $\quad$ Reducing health inequalities through promotion and implementation of reasonable adjustments

- $\quad$ Promoting improved health outcomes and increasing access to (and understanding of) general health services, consequently enabling social inclusion

The increasingly important role of supporting decision making around capacity, consent and best interests and in helping keep people safe is also recognised. There are currently 21,123 nurses registered as learning disability nurses with the NMC and this number will decrease soon due to retirement and a lack of commissioning from across the British Isles.

Yet learning disability nurses are essential to effectively contribute to the health care of people with an intellectual disability. This is carried out directly with the people we serve. But more importantly as we become rarer, to help other HP's and nurses effectively care for people with an intellectual disability.

Given the relatively small numbers of RNLD's it is important that we focus the skills, knowledge and competence to supporting access to generic health services and supporting people, with the most complex health needs - this is where RNLD's can have the biggest impact.

Internationally, education needs to also ensure they are preparing and developing RNLD's to fulfil their role and be skilled in assessing and delivering clinical, behavioural and psychological interventions and supporting other HP's wherever possible.

There is also a role for education to ensure all HP's have sufficient input within their programme to prepare them to support people with learning disabilities as they access the same services as everyone else which is their right and the true direction of policy.

\section{CONCLUSION}

How we describe people is very important - as it can lead to differential and often negative treatment. Additionally, despite the difficulties that they may encounter, some people with an intellectual disability may not be unhappy about having an intellectual disability, but may dislike the way that they are treated because of having an intellectual disability. Therefore, whilst not ignoring the disadvantages people suffer, be aware that is often more to do with ideologies and service design, that are the origins of their health issues - not their learning impairment. It is essential that professional education encompass' this as there is evidence to suggest that poor health is more to do with the social aspects effecting people with an intellectual disability, rather than physical aspects of associated syndromes.

Most of the issues about accessing good services, relationships and employment are not because of their having an intellectual disability, but because our society is designed in such a way as to develop barriers for them - even concerning something as basic as health care:

- $\quad$ They are more likely to have mental and physical health care issues than the general population

- Health staff often feel that they are inadequately trained and lack the knowledge and skills, to deal with the needs of people with an intellectual disability appropriately and require education in this area

- $\quad$ people responsible for ensuring that they have access to good quality services, treatment etc, do not understand what it means to have an intellectual disability

- $\quad$ diagnostic overshadowing and misdiagnosis may lead to poor health care and pain and suffering, even death

- $\quad$ Specialist nurses called Registered Nurses for Learning Disability (RNLD) have specialist training and can aid patients and other HP's

- $\quad$ There are specialist services available for people with an intellectual disability

- Individual HP's can make a real difference utilising listening and creative skills and making small adjustments

Strengthening the Commitment [1], recommends that those who commission, develop or deliver education should ensure that all nurses (not just learning disability) develop the core knowledge and skills necessary to work safely and appropriately with people with an intellectual disability who are accessing general health services. 
At Northumbia University we have developed a successful and unique way to enable this to happen by engaging actors with an intellectual disability to deliver specialised sessions to all undergraduate health professionals (Lord Willis, 2015) [37].

STC also recommends that there are sufficient number of appropriately prepared and supported RNLD's, that commissioners and service planners should have a clear vision for how they ensure the knowledge and skills of RNLD's are provided to the right people, in the right place, and at the right time and that they are able to collaborate effectively with general health services to address barriers and support the development of liaison and health facilitation roles. Countries outside of the UK should consider commissioning specialist learning disability nursing education as soon as possible.

There has been some good early success in relation to this policy. Student commissions have risen in Scotland and Wales, the UK Academic Network (developed as a result of Strengthening the Commitment) has developed a database that will hold data on student commissions, starts, completions and first job destinations. Accurate data will help identify trends and support workforce planning. The Network is also working closely with the Council of Deans to explore the education of other nursing fields in relation to the needs of people with an intellectual disability. A survey is being completed to identify current practice, examples of good practice and challenges. However it is important that progress continues and that we continue to strengthen the commitment to ensuring a well prepared and skilled nursing workforce that effectively identify and meet health needs, and reduce health inequalities for people with an intellectual disability.

\section{REFERENCES}

[1] Strengthening the Commitment: The Report of the UK Modernising Learning Disabilities Nursing Review Edinburgh Scottish Government 2012.

[2] Estimating Future Need for Adult Social Care Services for Peaople with Learning Disabilities in England Centre for Disability Research 2008.

[3] Fundamentals of Nursing: Concepts, process and practiceAustralia Pearson Publishing 2012.

[4] News Article MENCAP http://www.MENCAP.org.uk/news/ article/MENCAP-welcomes-government-mandate-nhscommissioning-board accessed 5 December 2012.

[5] Department of Health. Good Practice in Learning Disability Nursing Department of Health http://www.dh.gov.uk/en/ Publicationsandstatistics/Publications/PublicationsPolicyAnd Guidance/DH_081328
A Vision for Learning Disability Nursing. A discussion Document London UKLDNCN 2005.

[7] Nurse Education: Now and in the future; The Challenges for Nursing in the 21st century Nursing and Midwifery Council. http://www.nmc-uk.org/Get-involved/Consultations/Pastconsultations/By-year/Pre-registration-nursing-educationPhase-2/Nurse-education-Now-and-in-the-future/

[8] Death by Indifference; 74 Deaths and Counting. MENCAP http://www.MENCAP.org.uk/sites/default/files/documents/De ath $\% 20$ by $\% 20$ Indifference $\% 20-\% 2074 \% 20$ Deaths $\% 20$ and $\%$ 20counting.pdfn

[9] Healthcare for All. Report of the independent inquiry into access to healthcare for people with learning disabilities. Michael J. http://www.iahpld.org.uk.

[10] Women's Health: An Evidence Based Review World Health Organisation http://web.worldbank.org/WBSITE/EXTERNAL/ EXTABOUTUS/0,,contentMDK:23261965 pagePK:5112364 4 piPK:329829 theSitePK:29708,00.html

[11] The Politics of Disablement London Macmillan Education Ltd. 1991.

[12] Institutional Abuse Disability on Equal Terms Wiltshire. Sage 2008.

[13] United Nations Declaration of Rights of Disabled Persons. United Nations http://www.un.org/documents/ga/res/30/ ares30.htm

[14] Better services for the mentally handicapped London HMSO 1971.

[15] Helping Mentally Handicapped People in Hospital A Report to the Secretary of State for Social Services by the National Development Group for the Mentally Handicapped London HSMO 1978.

[16] Normalisation: the whole answer? Making Connections London The Open University Hodder and Stoughton 1989.

[17] A History of Learning Disabilities. Learning Disabilities Toward Inclusion London Churchill Livingston 2003.

[18] Independent, proud and different; celebrating our differences Disability Studies: Past, Present and Future Leeds The Disability Press 1997.

[19] Dimensions of Learning Disability London Balliere Tindall 1997.

[20] Fundamental Principles of Disability. Union of the Physically Impaired Against Segregation London UPIAS 1976.

[21] Making Connections. London.The Open University. Hodder and Stoughton 1989.

[22] Twentieth-Century Definitions of Mental Retardation. In Social Constructions of Mental Retardation. MNDDC http://www.mnddc.org/parallels2/pdf/99-MRI-MLW.pdf

[23] 'Towards an Affirmation Model of Disability'. Disability and Society.

[24] Self-advocacy, Civil Rights and the Social Model of Disability. ESRC Research Grant. Final Research Report www.leeds.ac.ukhttp://www.leeds.ac.uk/disabilitystudies/projects/selfadvocacy/final report.htm

[25] Death by Indifference MENCAP http://www.mencap.org.uk

[26] Health screening for people with learning disabilities by a community learning disability nursing service in Northern Ireland Journal of Advanced Nursing 10.

[27] Valuing people: a new strategy for learning disability for the $21^{\text {st }}$ London Department of Health 2001.

[28] Treat me Right: Better health care for people with a learning disability http://www.mencap.org.uk

[29] Getting it right together the implementation of recommendations 16, 17 and 20 from Promoting health, Supporting Inclusion Edinburgh NES 2004.

[30] The Human Rights Act C.42.

[31] Equality Act C. 15. 
[32] Getting Away with Murder. Disabled People's Experiences of Hate Crime in the UK. London Scope 2008.

[33] Disability Discrimination Act. London HMSO

[34] International Council of Nurses (2006) Advanced Nursing Practice. Blackwell Publishing Ltd

[35] Six lives: the provision of public services to people with learning disabilitiesLondonThe Stationary Office 2009.
[36] Understanding Disability. A Guide for Health Professionals China. hurchill Livingstone Elsevie 2008.

[37] Health Education England and the Nursing Midwifery Council. 2015. Lord Willis, Interdependent Chair - Shape of Caring Review.

Received on 19-03-2015

Accepted on 23-04-2015

Published on 07-08-2015

DOI: http://dx.doi.org/10.6000/2292-2598.2015.03.02.10

(C) 2015 Inglis et al.; Licensee Lifescience Global.

This is an open access article licensed under the terms of the Creative Commons Attribution Non-Commercial License (http://creativecommons.org/licenses/by-nc/3.0/) which permits unrestricted, non-commercial use, distribution and reproduction in any medium, provided the work is properly cited. 